Journal Indonesian Language Education and Literature Vol. 2, No. 1, 2016

http://www.syekhnurjati.ac.id/jurnal/index.php/jeill/

\title{
PENGEMBANGAN BUKU PENGAYAAN APRESIASI SASTRA \\ BERHURUF BRAILLE INDONESIA DENGAN MEDIA REGLET \\ BAGI SISWA TUNANETRA DI SEKOLAH INKLUSI KOTA SURAKARTA
}

\author{
Wati Istanti \\ Universitas Negeri Semarang \\ ungu_unnes@yahoo.co.id
}

\begin{abstract}
Abstrak
Tujuan yang akan dicapai dalam penelitian ini adalah (1) Menemukan permasalahan dan kebutuhan siswa tunanetra, perencanaan, dan prototype buku pengayaan apresiasi sastra dengan huruf Braille yang dapat dikembangkan di sekolah inklusi. (2) Mengembangkan prototype (draf) buku pengayaan apresiasi sastra dengan huruf Braille bagi siswa tunanetra di sekolah inklusi. (3) Menguji keefektifan penerapan buku pengayaan apresiasi sastra dari validator dengan huruf Braille bagi siswa tunanetra di sekolah inklusi. Metode dalam penelitian ini menggunakan desain penelitian pengembangan. Subjek penelitian ini adalah siswa tunanetra yang akan menggunakan produk buku pengayaan tersebut serta guru bahasa dan sastra Indonesia yang akan melakukan penilaian terhadap indikator pencapaian kompetensi dasar siswa tunanetra. Rencana kegiatan yang telah dilakukan dalam penelitian ini yaitu pengembangan desain buku pengayaan dengan tahapan: (1) studi pendahuluan; (2) tahap pengembangan; (3) tahap pengujian buku; (4) diseminasi hasil produk akhir yaitu buku pengayaan apresiasi sastra dengan huruf Braille. Dari hal tersebut, produk akhir berupa buku pengayaan apresiasi sastra dengan huruf Braille dapat digunakan oleh siswa tunanetra di kelas inklusif.
\end{abstract}

Kata kunci: anak, apresiasi, media, reglet, sastra

\begin{abstract}
Objectives to be achieved in this study were (1) Finding the problems and needs of blind students, planning, and prototype book enriching appreciation of literature in Braille that can be developed in school inclusion. (2) Develop prototype (draft) enrichment of literary appreciation books in Braille for blind students in school inclusion. (3) Test the effectiveness of the application of the enrichment of literary appreciation books of the validator in Braille for blind students in school inclusion. The method in this study research design development. The subjects were blind students who will use the product of the enrichment books and Indonesian language and literature teacher who will conduct an assessment of the indicators of achievement of the basic competencies of students with visual impairment. Plan activities that have been carried out in this research is the development of book design enrichment phases: (1) a preliminary study; (2) the development stage; (3) the testing stage book; (4) dissemination of the results of the final product, namely enrichment of literary appreciation books in Braille. The final product in the form of books enrichment appreciation of literature in Braille can be used by blind students in inclusive classrooms.
\end{abstract}

Keywords: appreciation, children, literature, media, reglet 


\section{Journal Indonesian Language Education and Literature Vol. 2, No. 1, 2016 http://www.syekhnurjati.ac.id/jurnal/index.php/jeill/}

\section{A. Pendahuluan}

Pembelajaran apresiasi sastra merupakan bagian dari pembelajaran yang mengajarkan kepada siswa untuk memiliki sikap kepekaan untuk menghargai hasil karya. Dari kepekaan menghargai hasil karya sastra tersebut, dapat diimplementasikan di dalam kehidupan sehari-hari. Sejalan dengan rumusan pengertian apresiasi di atas, Effendi (1973:33) mengungkapkan bahwa apresiasi sastra adalah kegiatan menggauli karya sastra secara sungguh-sungguh sehingga menumbuhkan pengertian, penghargaan, kepekaan pikiran kritis, dan kepekaan pikiran yang baik terhadap karya sastra.

Siswa berkebutuhan khusus dapat berpartisipasi dan mendapatkan hak yang sama dalam pembelajaran. Ketercapaian indikator tersebut dapat dilihat dari kompetensi dasar yang dicapai. Harapannya dalam pembelajaran apresiasi sastra, siswa berkebutuhan khususpun mampu disejajarkan dengan siswa reguler. Hal ini disebabkan siswa berkebutuhan khusus (tunanetra) memiliki kemampuan yang sama kuat dengan siswa regular ekolah inklusi menjadi salah satu ruang yang menyediakan kesempatan belajar bagi siswa berkebutuhan khusus, dalam hal ini siswa tunanetra. Di sekolah inklusi, potensi, bakat, dan kemampuan siswa tunanetra dihargai dengan baik. Selain itu, kompetensi kepribadian dan sosial siswa tunanetra juga dikembangkan dengan baik. Hal ini bertujuan untuk membawa siswa tunanetra mampu hidup mandiri dan sejajar dengan siswa pada umumnya. Dengan mengembangkan setiap potensi yang dimiliki oleh siswa tunanetra, mereka akan tumbuh menjadi individu yang mandiri, percaya diri, dan mampu bersosialisasi di tengah-tengah masyarakat.

Kegiatan pembelajaran dalam sekolah inklusi telah dirancang dengan baik. Kegiatan pembelajaran tersebut disesuaikan dengan kebutuhan siswa-siswinya. Selain itu, kegiatan-kegiatan dalam sekolah inklusi juga dirancang sesuai dengan tujuan pembelajarnya. Akan tetapi, ada kegiatan-kegiatan atau mata pelajaran yang belum berjalan maksimal. Salah satunya adalah pembelajaran apresiasi. Siswa berkebutuhan khusus tidak memiliki banyak kesempatan untuk belajar mengapresiasi. Padahal, pembelajaran apresiasi dapat membawa siswa berkebutuhan khusus menemukan pengalaman-pengalaman baru. Hal ini perlu menjadi salah satu pertimbangan penting dalam menyusun rancangan kegiatan pembelajaran.

Persoalan lain muncul pada penyediaan materi ajar, sarana, dan media pembelajaran. Sekolah inklusi masih belum menggunakan materi ajar atau sarana yang 


\section{Journal Indonesian Language Education and Literature Vol. 2, No. 1, 2016 http://www.syekhnurjati.ac.id/jurnal/index.php/jeill/}

sesuai dengan kebutuhan tunanetra. Media-media penunjang seharusnya digunakan untuk memudahkan siswa tunanetra dalam pembelajaran. Ada beberapa hal yang menjadi batasan siswa tunanetra. Hal ini akan menjadi masalah dalam proses pembelajaran. Oleh sebab itu, materi ajar, sarana, dan media pembelajaran perlu disesuaikan dengan kebutuhan siswa tunanetra. Dengan demikian, proses pembelajaran pada sekolah inklusi dapat berjalan dengan baik.

Berdasarkan berbagai persoalan di atas, diperlukan buku pengayaan sebagai sarana untuk mempermudah siswa tunanetra mengikuti pembelajaran apresiasi sastra. Buku pengayaan pembelajaran apresiasi sastra bagi siswa tunanetra perlu didesain dengan bentuk yang berbeda. Buku pengayaan tersebut disesuaikan dengan kebutuhan siswa tunanetra. Buku tersebut dapat disusun dengan huruf Braille yang dapat dibaca oleh siswa tunanetra. Hal ini bertujuan untuk memudahkan siswa tunanetra dalam proses belajar apresiasi sastra. Mereka diharapkan mampu belajar secara mandiri dalam mengapresiasi sastra. Dengan buku pengayaan tersebut, pembelajaran apresiasi sastra di sekolah-sekolah inklusi akan lebih mudah dilaksanakan.

Secara praktis, pembelajaran apresiasi sastra lebih efektif di sekolah reguler. Pembelajaran apresiasi sastra di sekolah reguler lebih menunjang dalam segi sarana dan prasarana. Selain itu, subjek pembelajaran pada sekolah reguler juga lebih representatif dalam pembelajaran apresiasi sastra. Akan tetapi, keberadaan pembelajaran apresiasi sastra pada sekolah inklusi juga perlu diseimbangkan dengan kondisi sekolah reguler. sekolah inklusi sebagai ruang belajar bagi siswa berkebutuhan khusus tidak boleh dipandang sebelah mata. Kurikulum sekolah inklusi perlu disejajarkan dengan sekolah reguler agar siswa berkebutuhan khusus memiliki kompetensi yang sama dengan siswa reguler pada umunya.

Berdasarkan kebutuhan-kebutuhan siswa tunanetra dalam pembelajaran apresiasi sastra, buku pengayaan apresiasi sastra berhuruf Braille Indonesia dengan media Reglet dapat digunakan secara efektif dalam pembelajaran apresiasi sastra bagi siswa tunanetra. Dengan buku pengayaan berhuruf Braille dan media Reglet, siswa tunanetra mampu mengembangkan potensinya dalam mengapresiasi karya sastra. Siswa tunanetra juga akan memiliki kedudukan yang sama dengan siswa reguler dalam hal pembelajaran apresiasi sastra. 
Berdasarkan latar belakang di atas dapat diidentifikasi berbagi masalah yang dirumuskan sebagai berikut.

1. Bagaimanakah bentuk studi pendahuluan yang dapat dilakukan untuk pengembangan buku pengayaan apresiasi sastra dengan huruf Braille bagi siswa tunanetra di sekolah inklusi?

2. Bagaimanakah bentuk pengembangan prototype (draf) buku pengayaan apresiasi sastra dengan huruf Braille bagi siswa tunanetra di sekolah inklusi?

3. Bagaimanakah hasil uji validasi keefektifan buku pengayaan apresiasi sastra dengan huruf Braille bagi siswa tunanetra di sekolah inklusi?

Secara rinci kontribusi penelitian ini dapat diuraikan sebagai berikut.

1. Pembangunan Pengembangan IPTEKS

Media Pengembangan IPTEKS khususnya dalam kompetensi dasar apresiasi sastra akan dapat dikembangkan lebih lanjut menjadi buku pengayaan dengan huruf Braille.

2. Pengembangan Institusi

Kontribusi penelitian dalam hal pengembangan buku pengayaan apresiasi sastra dengan huruf Braille bagi siswa tunanetra di sekolah inklusi ini akan sangat membantu dalam mengembangkan sekolah-sekolah yang membuka kelas inklusif.

3. Kebutuhan serta Potensi Masyarakat Jika buku pengayaan apresiasi sastra ini dapat diwujudukan, disosialisasikan dan dimiliki oleh semua sekolah yang membuka kelas inklusif bagi siswa tunanetra maka orang tua dan masyarakat akan merasa bahwa anak-anak mereka memperoleh hak yang sama terhadap ketercapaian indikator pembelajaran di sekolah.

\section{B. Metode Penelitian}

Penelitian dengan judul Pengembangan Buku Pengayaan Apresiasi Sastra Berhuruf Braille Indonesia dengan Media Reglet bagi Siswa Tunanetra di Sekolah Inklusi Kota Surakarta ini secara metodologis menggunakan pendekatan research and development $(R \& D)$ atau dengan desain penelitian pengembangan. Penelitian ini berorientasi pada pengembangan produk yaitu buku pengayaan apresiasi sastra yang meliputi puisi (lama dan modern), cerpen, dan teks drama berhuruf Braille Indonesia dengan media reglet, 
yang dikhususkan bagi siswa tunanetra. Harapannya dengan media tersebut yaitu buku pengayaan apresiasi sastra, siswa tunanetra di sekolah inklusi dapat mengikuti pembelajaran apresiasi sastra dengan baik. Indikator terhadap kompetensi dasar apresiasi sastra seperti menganalisis cerita pendek, membaca puisi, dan memahami teks cerpen dapat tercapai dengan maksimal.

Penelitian ini dilaksanakan dengan mengikuti hakikat prosedur penelitian pengembangan yang berbentuk riset operasional (Gall \& Borg dalam Sugiyono 2009). Prosedur pengembangan yang diikuti tersebut meliputi tahapan: (1) studi pendahuluan; (2) tahap pengembangan; (3) tahap pengujian; (4) diseminasi hasil produk akhir berupa buku pengayaan apresiasi sastra berhuruf Braille Indonesia dengan media reglet bagi siswa tunanetra di sekolah inklusi. Dan pada penelitian ini hanya sampai pada tahap pengujian produk.

\section{Hasil dan Pembahasan}

Hasil penelitian yang dipaparkan meliputi empat hal, yaitu (1) Menemukan permasalahan dan kebutuhan siswa tunanetra, perencanaan, dan prototype buku pengayaan apresiasi sastra berhuruf braille Indonesia dengan media reglet bagi siswa tunanetra di sekolah inklusi kota Surakarta, (2) prototype (draf) buku pengayaan apresiasi sastra berhuruf braille Indonesia dengan media reglet bagi siswa tunanetra di sekolah inklusi kota Surakarta, (3) keefektivan penerapan buku pengayaan apresiasi sastra berhuruf braille Indonesia dengan media reglet bagi siswa tunanetra di sekolah inklusi kota Surakarta, dan (4) keberterimaan buku pengayaan apresiasi sastra berhuruf braille Indonesia dengan media reglet bagi siswa tunanetra di sekolah inklusi kota Surakarta. Berikut jabaran lengkapnya.

1. Permasalahan dan kebutuhan siswa tunanetra, perencanaan, dan prototype buku pengayaan apresiasi sastra berhuruf braille Indonesia dengan media reglet bagi siswa tunanetra di sekolah inklusi kota Surakarta

Analisis kebutuhan merupakan langkah awal memahami kebutuhan dan persepsi siswa terhadap buku pengayaan. Hasil analisis kebutuhan tersebut digunakan sebagai acuan untuk mengembangkan pengembangan buku pengayaan apresiasi sastra berhuruf braille Indonesia dengan media reglet bagi siswa tunanetra di sekolah inklusi sesuai persepsi siswa. 
Persepsi siswa terhadap pengembangan buku pengayaan apresiasi sastra berhuruf braille Indonesia dengan media reglet bagi siswa tunanetra di sekolah inklusi meliputi dua aspek. Kedua aspek tersebut meliputi (1) Pengembangan buku pengayaan apresiasi sastra berhuruf braille Indonesia dengan media reglet bagi siswa tunanetra di sekolah inklusi menurut persepsi siswa, dan (2) harapan siswa terhadap buku pengayaan apresiasi sastra berhuruf braille Indonesia dengan media reglet bagi siswa tunanetra di sekolah inklusi.

\section{Keefektivan Penerapan Buku Pengayaan Apresiasi Sastra Berhuruf Braille Indonesia dengan Media Reglet bagi Siswa Tunanetra di Sekolah Inklusi}

Uji keefektivan berkenaan dengan pemberian buku pengayaan apresiasi sastra berhuruf braille Indonesia dengan media reglet bagi siswa tunanetra di sekolah inklusi juga dilakukan dengan cara membandingkan perbedaan hasil postes kelompok siswa tunanetra yang diberikan buku pengayaan dengan yang tidak di sekolah inklusif yang sama. Hasil perbandingan penerapan pengembangan buku pengayaan apresiasi sastra ini dianalisis dengan teknik uji-t (t-test) independent.

Berdasarkan hasil penghitungan ini diketahui bahwa perbedaan nilai rata-rata kelompok siswa tunanetra yang diberi buku pengayaan dengan kelompok siswa tunanetra yang tidak diberi buku pengayaan pada masing-masing sekolah inklusif sebagai berikut:

a. Hasil uji-t perbandingan skor postes kelompok yang diberi buku pengayaan apresiasi sastra dengan postes kelompok yang tidak diberi media pembelajaran ekspresi lisan sastra di sekolah inklusif di SMA 2 diperoleh harga t hitung sebesar 3,38

b. Hasil uji-t perbandingan skor postes kelompok yang diberi buku pengayaan apresiasi sastra dengan postes kelompok yang tidak diberi buku pengayaan apresiasi sastra di sekolah inklusif di SMA 5 diperoleh harga t hitung sebesar 5,42

c. Hasil uji-t perbandingan skor postes kelompok yang diberi buku pengayaan apresiasi sastra dengan postes kelompok yang tidak diberi buku pengayaan apresiasi sastra di sekolah inklusif di SMA 2 Muhammadiyah diperoleh harga t hitung sebesar 5,09

Dari hasil di atas dapat dinyatakan bahwa kompetensi siswa tunanetra dengan diberi buku pengayaan apresiasi sastra berhuruf braille Indonesia dengan media reglet bagi siswa tunanetra lebih baik daripada kompetensi siswa tunanetra yang tidak diberi buku pengayaan. Perbedaan ini signifikan sehingga menandakan bahwa pemberian buku pengayaan apresiasi sastra berhuruf braille Indonesia dengan media reglet bagi siswa 


\section{Journal Indonesian Language Education and Literature Vol. 2, No. 1, 2016 http://www.syekhnurjati.ac.id/jurnal/index.php/jeill/}

tunanetra lebih efektif dibandingkan dengan yang tidak diberi buku pengayaan apresiasi sastra di kelas inklusif.

Uji keefektivan berikutnya berkenaan dengan perbandingan kompetensi siswa yang menggunakan buku pengayaan apresiasi sastra dengan yang tidak menggunakan buku pengayaan apresiasi sastra dilakukan dengan cara membandingkan perbedaan hasil postes-pretes siswa tunawicara yang diberi buku pengayaan apresiasi sastra berhuruf braille Indonesia dengan media reglet dan hasil skor postes-pretes siswa yang tidak diberi buku pengayaan apresiasi sastra berhuruf braille Indonesia dengan media reglet bagi siswa tunanetra.

Hasil perbandingan pemberian buku pengayaan apresiasi sastra berhuruf braille Indonesia dengan media reglet dengan yang tidak bagi siswa tunanetra di kelas inklusif ini dianalisis dengan teknik uji-t (t-test) independent.

Berdasarkan hasil penghitungan ini diketahui bahwa nilai rata-rata perbedaan skor postes-pretes kelompok siswa tunanetra yang diberi buku pengayaan dengan skor postespretes kelompok siswa tunanetra yang tidak diberi buku pengayaan pada sekolah inklusf di Kota Surakarta sebagai berikut.

a. Hasil uji-t perbandingan perbedaan skor postes-pretes kelompok yang diberi buku pengayaan apresiasi sastra dengan postes kelompok yang tidak diberi buku pengayaan apresiasi sastra di sekolah inklusif di SMA 2 diperoleh harga t hitung sebesar 3,99

b. Hasil uji-t perbandingan perbedaan skor postes-pretes kelompok yang diberi buku pengayaan apresiasi sastra dengan postes kelompok yang tidak diberi buku pengayaan apresiasi sastra di sekolah inklusif di SMA 5 diperoleh harga t hitung sebesar 6,76

c. Hasil uji-t perbandingan perbedaan skor postes-pretes kelompok yang diberi buku pengayaan apresiasi sastra dengan postes kelompok yang tidak diberi buku pengayaan apresiasi sastra di sekolah inklusif di SMA 8 diperoleh harga t hitung sebesar 6,42

Dari hasil di atas dapat dinyatakan bahwa kompetensi siswa tunanetra dengan diberi buku pengayaan apresiasi sastra berhuruf braille Indonesia dengan media reglet lebih baik daripada kompetensi siswa tunanetra yang tidak diberi media. Perbedaan ini signifikan sehingga menandakan bahwa pemberian buku pengayaan apresiasi sastra berhuruf braille Indonesia dengan media reglet lebih efektif dibandingkan dengan yang tidak diberi media pembelajaran ekspresi lisan sastra di kelas inklusif. 


\section{Keberterimaan Produk Penelitian}

Keefektifan buku pengayaan apresiasi sastra berhuruf braille Indonesia dengan media reglet bagi siswa tunanetra untuk meningkatkan keterampilan bersastra bagi siswa tunanetra di kelas inklusif. Selain diperuntukan khusus untuk siswa tunanetra di kelas inklusif, buku pengayaan apresiasi sastra berhuruf braille Indonesia dengan media reglet juga telah disesuaikan untuk pengguna umum yang membuat pengguna dapat secara langsung belajar dan berlatih keterampilan berapresiasi sastra saat menggunakannya.

Buku pengayaan apresiasi sastra berhuruf braille Indonesia dengan media reglet bagi siswa tunanetra ini lebih menarik dibandingkan dengan buku pengayaan yang lain sehingga pembelajaran menjadi lebih bermakna. Selain itu, materi tentang wawasan keberagaman nusantara yang diintegrasikan dalam media ini mampu membantu peserta didik dalam memperoleh informasi tentang kondisi sosial budaya yang ada di Indonesia.

\section{1) Penyajian Produk Sesuai dengan Karakteristik Kebutuhan Pengguna}

Anak berkebutuhan khusus seperti tunanetra memiliki hak yang sama berkait indikator pencapaian dalam kompetensi dasar apresiasi sastra. Maksudnya mereka (siswa reguler/berkebutuhan khusus) juga harus mampu mengapresiasi sastra secara tulis maupun lisan. Namun, terkadang siswa tunanetra kesulitan dalam mengimplementasikan kompetensi dasar tersebut. Hal itu dikarenakan kompetensi dasar yang berkait dengan kegiatan membaca. Sehingga siswa tunanetra memerlukan media yang tepat dalam mengikuti pembelajaran apresiasi sastra di kelas inklusif agar indikator yang dicapai sesuai dengan harapan. Media tersebut tentunya akan membantu siswa tunanetra dalam mengikuti kegiatan pembelajaran dengan kompetensi dasar apresiasi sastra secara maksimal. Meskipun hal itu tidak harus sesempurna seperti siswa normal pada umumnya, akan tetapi bisa membantu mereka untuk memperoleh hak yang sama dalam kegiatan pembelajaran.

Media yang dipilih harus diperhatikan sesuai dengan sasaran penggunanya. Dalam hal ini, siswa tunanetra merupakan pengguna media tersebut untuk kompetensi dasar apresiasi sastra. Maka media yang sesuai yang nantinya dapat dipahami oleh siswa tunanetra itu sendiri maupun guru yang akan memberikan penilaian adalah media dengan basis braille dengan media reglet. Media pembelajaran berbasis braille dengan media reglet tersebut akan dapat membantu memberikan ungkapan bahasa verbal bagi siswa tunanetra, serta guru pun akan dapat memberikan penilaian terhadap bahasa verbal yang 


\section{Journal Indonesian Language Education and Literature Vol. 2, No. 1, 2016 http://www.syekhnurjati.ac.id/jurnal/index.php/jeill/}

disampaikan siswa tunanetra melalui media tersebut. Sehingga hak yang sama mengenai ketercapaian kompetensi dasar dalam pembelajaran juga dirasakan bagi siswa tunanetra. Dan esensi sekolah/kelas inklusif dapat sesuai dengan porsi bahwa antara siswa reguler dan siswa berkebutuhan khusus memiliki hak yang sama.

\section{2) Materi yang Bermuatan Keberagaman Nusantara Membantu Guru dalam Membekali Peserta Didik tentang Pengenalan Kebudayaan Indonesia}

Buku pengayaan apresiasi sastra berhuruf braille Indonesia dengan media reglet bagi siswa tunanetra ini memiliki beberapa keungggulan jika dibandingkan dengan buku pada umumnya khususnya bagi siswa tunanetra. Peserta didik sangat terbantu untuk belajar mengenai apresiasi sastra.

Buku pengayaan apresiasi sastra berhuruf braille Indonesia dengan media reglet bagi siswa tunanetra memiliki korelasi dengan kurikulum yang ada di sekolah, sehingga guru akan terbantu dengan penggunaan buku. Dengan mengintegrasikan kebudayaan Indonesia pada buku pengayaan, membuat tujuan pembelajaran bahasa Indonesia yang memiliki keterkaitan dengan budaya Indonesia dapat tercapai.

\section{3) Jangkauan Produk ke Depan}

Dalam konteks penelitian ini, buku pengayaan apresiasi sastra berhuruf braille Indonesia dengan media reglet bagi siswa tunanetra yang peneliti susun memiliki beberapa keunggulan, baik keunggulan yang dilihat dari segi bentuk fisik maupun isi. Sebagai sebuah produk pengembangan, media ini berpeluang untuk dipasarkan dalam skala besar karena nilai kebaruan dan diferensiasinya. Produk ini berpotensi untuk memenuhi kebutuhan peserta didik dan guru terhadap buku pengayaan untuk pembelajaran apresiasi sastra.

Materi dalam media ini juga diintegrasikan dengan wawasan mengenai kebudayaan Indonesia yang sangat berguna bagi peserta didik dalam memahami budaya bangsa Indonesia.

Rencana pemasaran produk buku pengayaan apresiasi sastra berhuruf braille Indonesia dengan media reglet bagi siswa tunanetra ini perlu segera ditindaklanjuti. Salah satu upaya tindak lanjut yang dilakukan adalah dengan menyusun strategi pengembangan. Strategi pengembangan ini penting untuk dirumuskan dan dijalankan dalam rangka pengembangan produk media dengan jangkauan pemasaran yang lebih luas. Berdasarkan analisis lingkungan internal dan eksternal pengembangan buku pengayaan, dapat 


\section{Journal Indonesian Language Education and Literature Vol. 2, No. 1, 2016 http://www.syekhnurjati.ac.id/jurnal/index.php/jeill/}

diketahui faktor kekuatan, kelemahan, peluang, dan ancaman/ tantangan yang dihadapi.

Aspek lingkungan internal yang menjadi faktor peguat, yaitu (1) keunggulan dari segi fisik, buku pengayaan apresiasi sastra berhuruf braille Indonesia dengan media reglet bagi siswa tunanetra yang sesuai kebutuhan peserta didik memudahkan mobilitas media bagi pengguna, (2) materi wawasan keberagaman nusantara mampu memberikan pengetahuan kepada peserta didik tentang keberagaman Indonesia. Adapun aspek lingkungan internal yang menjadi faktor kelemahan yaitu (1) penggunaan buku yang harus hati-hati.

Sementara itu aspek lingkungan eksternal yang menjadi penguat pengembangan buku pengayaan apresiasi sastra berhuruf braille Indonesia dengan media reglet bagi siswa tunanetra di sekolah inklusi, yaitu (1) tingginya kebutuhan guru dan siswa tunanetra terhadap buku pengayaan, (2) minimnya ketersediaan bahan ajar dan media pembelajaran yang mumpuni untuk digunakan dalam pembelajaran apresiasi sastra bagi siswa tunanetra, (3) dukungan kurikulum 2013 terhadap pembelajaran bahasa Indonesia dalam konteks berwawasan keberagaman nusantara. Adapun lingkungan eksternal yang menjadi penghambat yaitu (1) ketergantungan pengajar terhadap buku sehingga menurunkan motivasi dan kreativitas dalam mengajar, (2) Sulitnya permodalan untuk promosi dan penggunaan produk dalam skala makro.

Selanjutnya setelah keempat faktor tersebut diketahui, dapat dianalisis dan dirumuskan alternatif strategi pengembangan produk buku pengayaan apresiasi sastra berhuruf braille Indonesia dengan media reglet bagi siswa tunanetra di sekolah inklusi. Berdasarkan identifikasi faktor-faktor yang menjadi kekuatan, kelemahan, peluang, dan ancaman, kemudian dilakukan perumusan strategi pengembangan dengan menggunakan analisis SWOT, yaitu 1) stregth (kekuatan), 2) weaknes (kelemahan), 3) opportunity (peluang), dan 4) threats (ancaman).

Strategi yang pertama yaitu (1) Menggandeng berbagai instansi yang terkait seperti Dinas Pendidikan untuk bersama mengembangkan buku pengayaan apresiasi sastra berhuruf braille Indonesia dengan media reglet bagi siswa tunanetra di sekolah inklusi. (strategi S-O), (2) Pengujicobaan buku pengayaan apresiasi sastra berhuruf braille Indonesia dengan media reglet bagi siswa tunanetra di sekolah inklusi sebagai pioner sekaligus inspirator bagi peneliti lain untuk mengembangkan buku pengayaan dengan konteks nilai-nilai keberagaman nusantara yang lainnya (strategi W-O), (3) 


\section{Journal Indonesian Language Education and Literature Vol. 2, No. 1, 2016 http://www.syekhnurjati.ac.id/jurnal/index.php/jeill/}

Pengoptimalan sosialisasi penggunaan buku pengayaan bagi pengguna, termasuk latar belakang dan tujuan awal dari pengembangan buku pengayaan apresiasi sastra berhuruf braille Indonesia dengan media reglet bagi siswa tunanetra di sekolah inklusi (strategi ST), dan (4) Memaksimalkan promosi yang menarik kepada lembaga pengembangan multimedia dan pemerhati pendidikan bahasa Indonesia bagi siswa tunanetra untuk pemanfaatan produk secara masal dalam skala makro (strategi W-T).

\section{Simpulan dan Saran}

Berdasarkan hasil dan pembahasan, penelitian ini dapat disimpulkan sebagai berikut.

1) Pada tahap pertama, dilakukan studi pendahuluan guna mengetahui masalah dan kebutuhan dalam pembelajaran apresiasi sastra di sekolah inklusi, khususnya bagi siswa tunanetra. Adapun hasil dari analisis masalah dan kebutuhan, diketahui bahwa buku pengayaan apresiasi sastra dengan huruf braille dibutuhkan untuk menunjang pembelajaran bagi siswa tunanetra di sekolah inklusi.

2) Prototipe buku pengayaan diujikan kepada pakar/ahli. Hal tersebut digunakan sebagai tahap validasi produk. Hasil tersebut digunakan pula sebagai acuan pengembangan berikutnya. Selain itu, produk juga diuji secara primer dalam skala kecil.

3) Tahap terakhir dalam penelitian ini adalah uji keefektifan produk secara luas. Hal ini digunakan untuk mengetahui keefektifan produk dalam menunjang pembelajaran apresiasi sastra bagi siswa tunanetra di sekolah inklusi. Adapun uji keefektifan tersebut diketahui melalui peningkatan pengetahuan dan keterampilan siswa dalam pembelajaran apresiasi sastra dalam menggunakan buku pengayaan tersebut.

Penelitian ini dilakukan guna meningkatkan mutu pembelajaran apresiasi sastra bagi siswa tunanetra di sekolah inklusi. Penelitian ini memberikan peluang lebih luas bagi penelitian-penelitian terkait, khususnya dalam pembelajaran di sekolah inklusi. Oleh sebab itu, penelitian ini dapat ditindaklanjuti dalam penelitian-penelitian berikutnya.

\section{Daftar Pustaka}

Aminuddin. 1987. Pengantar Apresiasi Karya Sastra..Bandung: Sinar Baru Algesindo.

Gall, D. Meredith. Joyce P.Gall \& Waletr R. Borg. 2003. Educational Research and Introduction. New York: Pearson Publishing. 


\section{Journal Indonesian Language Education and Literature Vol. 2, No. 1, 2016}

http://www.syekhnurjati.ac.id/jurnal/index.php/jeill/

Kemendikanas. 2010. Modul Pelatihan Pendidikan Inklusif. Editor Dr. Budiyanto. Kementerian Pendidikan Nasional.

Muhadjir, Noeng. 1998. Metode Penelitian Kualitatif. Jakarta: Gramedia.

Sugiyono. 2010. Metode Penelitian Pendidikan: Pendektan Kuantitatif, Kualitatif, dan $R \& D$. Bandung: Alfabeta. 